\title{
Colonização e lesão em fêmeas ingurgitadas do carrapato Rhipicephalus sanguineus causadas pelo fungo Metarhizium anisopliae
}

\author{
Colonization and lesions on engorged female Rhipicephalus sanguineus, caused by \\ Metarhizium anisopliae
}

\author{
Marcos Valerio Garcia ${ }^{1}$ Antonio Carlos Monteiro ${ }^{2}$ Matias Pablo Juan Szabó ${ }^{3}$
}

\section{RESUMO}

\begin{abstract}
O presente trabalho teve como objetivo verificar a forma de penetração do fungo Metarhizium anisopliae [METSCH. (SOROKIN, 1883)] em carrapatos da espécie Rhipicephalus sanguineus (LATREILLE, 1806), assim como as lesões infringidas nos tecidos internos do ácaro. A forma de aderência e penetração do fungo foi estudada através da microscopia eletrônica de varredura e a ação do fungo nos tecidos internos avaliada em secções histológicas convencionais. Para observação destes eventos, realizaramse infecções experimentais em 11 grupos de fêmeas ingurgitadas do carrapato $\boldsymbol{R}$. sanguineus contendo 12 fêmeas ingurgitadas cada. Para tal, as fêmeas ingurgitadas foram banhadas durante 3 minutos, sob agitação manual, em suspensão com concentração $10^{8}$ conídios $/ m L$. No caso dos grupos controle o banho foi realizado apenas no veículo da suspensão. Os carrapatos foram processados para histopatologia e microscopia eletrônica em diversos tempos após a infecção, a saber: 1 e 18h, e um, dois, três, quatro, cinco, seis, sete, nove e onze dias. Observou-se que a maior parte dos conídios germinou em até $18 \mathrm{~h}$ após a inoculação e que o fungo penetrou no ácaro através do tegumento $48 \mathrm{~h}$ após a infecção. Após a penetração, o fungo invadiu o corpo do hospedeiro promovendo uma colonização difusa, sem preferência aparente por tecidos específicos. Dentre as lesões nos tecidos internos do ácaro, ressalta-se o rompimento da parede intestinal e vazamento do conteúdo para a hemocele. A morte do hospedeiro ocorreu entre 96 e $120 \mathrm{~h}$ pós-infecção, e a esporulação do patógeno sobre o cadáver do ácaro iniciou-se em torno de 120 a 144 h pós-infecção. Espera-se, com este trabalho, contribuir para o desenvolvimento e viabilização de técnicas de controle biológico dos carrapatos por fungos como alternativa ao uso de acaricidas.
\end{abstract}

Palavras-chave: controle biológico, controle microbiano, fungo entomopatogênico, histopatologia, microscopia eletrônica.

\section{ABSTRACT}

The objective of this work was to verify the penetration of the fungus Metarhizium anisopliae [METSCH. (SOROKIN, 1883)], in to the Rhipicephalus sanguineus ticks (LATREILLE, 1806), as well as the lesions caused in the tissues of the acarus. The form of adherence and penetration of the fungus in the deep tissue was studied through scanning microscopy and the fungus action on the internal tissues was evaluated in conventional hystological sections. In order to evaluate these events, experimental infestations were conducted in 11 engorged females groups of the tick $\boldsymbol{R}$. sanguineus, containing 12 engorged females in each. Aiming this goal the engorged females were submited to a bath in a conidial suspension in a concentration of $10^{8}$ conidia/mL during three minutes under manual agitation. In case of control groups the bath was done only in the suspension vehicle. Ticks were processed for histological and scanning microscopy surveys at different intervals after the infection: 1 and $18 \mathrm{~h}$ and one, two, three, four, five, six, seven, eight, nine and eleven days. It has been observed that the major part of the conidians have germinated within $18 \mathrm{~h}$ after the inoculation and that the fungus the penetrated the acarus body, trough it's tegument $48 \mathrm{~h}$ after the infection. After the penetration the fungus colonized the tick's body in a diffuse manner, without any preference for a specific tissue. Among the lesions caused by the fungus, rupture of the tick's intestinal wall and the dispersion of the fluid into the hemocel were the most outstanding features. Death of the host occurred $96 \mathrm{~h}$ posinfection and the sporulation of the pathogen over the dead acarus began 120 to $144 \mathrm{~h}$ pos-infection. This work aims to

${ }^{1}$ Biólogo, Doutorando, Programa de Pós-graduação em Microbiologia, Faculdade de Ciências Agrárias e Veterinárias (FCAV),

Universidade Estadual Paulista (UNESP). E-mail: marcos@fcav.unesp.br

${ }^{2}$ Biólogo, Departamento de Produção Vegetal, FCAV, UNESP. E-mail: montecar@fcav.unesp.br

${ }^{3}$ Médico Veterinário, Departamento de Patologia Animal, FCAV, UNESP e Universidade de Franca. E-mail: szabo@fcav.unesp.br 
contribute to the establishement of techniques for biological control of the ticks by fungus as an ecological alternative for acaricides.

Key words: biological control, entomopathogenic fungus, histopathology, microbialcontrol.

\section{INTRODUÇÃO}

Rhipicephalus sanguineus (LATREILLE, 1806), um carrapato cosmopolita, é provavelmente o ixodídeo de mais ampla distribuição mundial (PEGRAM et al., 1987) e representa a única espécie do gênero Rhipicephalus (ARAGÃO \& FONSECA, 1961) no Brasil. Sua descrição tem sido freqüentemente associada à presença do hospedeiro cão (ARAGÃO, 1936; RIBEIRO et al., 1997; LABRUNA \& PEREIRA, 2001; SZABÓ et al., 2001), estando adaptado a cães de domicílios em cidade. Diversos microorganismos patogênicos podem ser veiculados pelo $R$. sanguineus (ESTRADA-PENÃ \& JONGEJAN, 1999; WALKER et al., 2000) e alguns são potencialmente transmissíveis ao homem, como a Rickettsia rickettsi, agente da febre maculosa e Rickettsia conorii, agente da febre botonosa, entre outros. É essencial o controle desta espécie de carrapato como forma de se estabelecer melhores condições sanitárias aos animais domésticos, notadamente o cão.

O controle de carrapatos é feito correntemente por meio de compostos químicos sintéticos (acaricidas). Recentemente MILLER et al. (2001) observaram desenvolvimento de resistência do ectoparasita a alguns princípios ativos utilizados nessas formulações. Uma das alternativas aos acaricidas é o controle biológico, especialmente com fungos, que tem se mostrado uma técnica eficaz e promissora, como previamente verificado por BITTENCOURT et al. (1997). BARBOSA et al. (1997) observaram redução no percentual de ecdise de larvas de $\boldsymbol{R}$. sanguineus com o aumento na concentração de esporos de $\boldsymbol{B}$. bassiana. MONTEIRO et al. (1998) demonstraram que a concentração de $10^{8}$ con./mL causou morte em $95 \%$ das larvas, 20 dias após a infecção. Estudando a patogenicidade de $\boldsymbol{M}$. anisopliae em diferentes estádios do carrapato $R$. sanguineus, SAMISH et al. (2001) constataram alta mortalidade em todos os instares não alimentados. Porém, existem poucos estudos que relatam os mecanismos da infecção de carrapatos por fungos. BITTENCOURT et al. (1999) mostraram, por meio de microscopia eletrônica de varredura, a adesão, germinação e formação do apressório, confirmando a hipótese de que $\boldsymbol{M}$. anisopliae penetra em $\boldsymbol{B}$. microplus pela cutícula.

Nota-se, contudo, que há falta de maiores informações e conhecimentos a respeito dos fenômenos ou eventos que envolvem o mecanismo de patogenicidade de fungos sobre carrapatos. Este trabalho objetivou demonstrar a adesão, germinação, penetração e colonização, assim como as lesões infringidas pelo fungo no ácaro. Espera-se, desse modo, contribuir para a compreensão do mecanismo de patogenicidade de fungos sobre carrapatos, para a seleção de linhagens mais virulentas, e conseqüentemente para viabilização de técnicas de controle de carrapatos por fungos, como alternativa ao uso de acaricidas.

\section{MATERIAL E MÉTODOS}

O fungo utilizado foi o Metarhizium anisopliae, isolado E9, obtido de Deois flavopicta (cigarrinha das pastagens), e mantido em cultura estoque no Laboratório de Microbiologia do Departamento de Produção Vegetal da Faculdade de Ciências Agrárias e Veterinárias (FCAV) da Universidade Estadual Paulista (UNESP), Campus de Jaboticabal, SP. O isolado foi cultivado em placas de Petri contendo meio de batata, dextrose e ágar (BDA), acondicionadas em estufa a $27^{\circ} \mathrm{C}$, no escuro, por aproximadamente 12 dias.

O carrapato utilizado foi o Rhipicephalus sanguineus, proveniente da colônia mantida no Laboratório de Imunopatologia do Departamento de Patologia Animal da FCAV-UNESP. Para manutenção da colônia, os carrapatos foram alimentados em coelhos isentos de contato prévio com o ácaro. Durante a alimentação, os carrapatos ficaram restritos aos hospedeiros por câmaras de plástico transparente (BECHARA et al., 1989) coladas com material atóxico (Britannia Adhesives P4104 Latex, Inglaterra) ao seu dorso depilado. Para ecdise dos instares ingurgitados, bem como para sua simples manutenção, os ácaros foram mantidos em estufa tipo BOD (temperatura de $28^{\circ} \mathrm{C}$ e umidade relativa de $80 \%$ ).

As suspensões de conídios foram obtidas a partir das colônias jovens do fungo. Utilizou-se, para as infecções, $20 \mathrm{~mL}$ de uma suspensão preparada em solução de Tween $80^{\circledR}$ a $0,1 \%$ (v/v), contendo uma concentração de $10^{8}$ con. $/ \mathrm{mL}$.

Para infecção das fêmeas ingurgitadas, foram utilizados 11 grupos, compostos por 12 fêmeas ingurgitadas de $\boldsymbol{R}$. sanguineus. Em cada grupo, as fêmeas foram lavadas em água deionizada, desinfectadas em solução de hipoclorito de sódio a 
$3 \%(\mathrm{v} / \mathrm{v})$, enxaguadas abundantemente com água deionizada e secas em papel de filtro. Na seqüência, os grupos foram banhados em $20 \mathrm{~mL}$ da suspensão de conídios durante 3 minutos, o excesso de líquido retirado com papel de filtro, e as fêmeas acondicionadas individualmente em tubos transparentes etiquetados e mantidos em BOD a $27^{\circ} \mathrm{C}$. Os tempos de colheita das fêmeas infectadas e seus respectivos controles foram estabelecidos em 1 e $18 \mathrm{~h}$, um, dois, três, quatro, cinco, seis, sete, nove e onze dias. Após colheita em cada tempo preestabelecido, as fêmeas de $\boldsymbol{R}$. sanguineus foram divididas em duas parcelas: uma destinada ao preparo histológico e outra para a microscopia eletrônica.

O material destinado para análise histopatológica ( 6 fêmeas controle e 6 fêmeas do grupo teste, em cada tempo) foi imerso em formol tamponado por $12-24 \mathrm{~h}$. As fêmeas ingurgitadas tiveram seus tegumentos cuidadosamente perfurados com agulhas finas $(13 \times 4,5)$, para permitir melhor difusão do fixador. Os materiais fixados foram submetidos à inclusão em parafina de acordo com técnicas rotineiras de histologia. Posteriormente cortes longitudinais seriados foram realizados para obtenção de secções representativas dos tecidos do ácaro infectado e do controle. As secções foram coradas com os corantes hematoxilina-eosina (visualização das alterações gerais dos tecidos) e coloração Gomori Metanamine Stain (GMS), específica para fungos.

As fêmeas destinadas à análise em microscópio eletrônico de varredura (6 do grupo controle e 6 do grupo teste, em cada tempo), foram fixadas em glutaraldeido a $3 \%$, em tampão de fosfato de potássio a 0,05M e pH 7,4 por 72h. Em seguida, foram lavadas em solução tampão pura, por seis vezes consecutivas, a intervalos de 20 minutos. Posteriormente foram desidratadas em álcool etílico, secas em secador de ponto crítico em $\mathrm{CO}_{2}$, recobertas com partículas de ouro $(35 \mathrm{~nm})$ e elétron-micrografadas em microscópio eletrônico de varredura JEOL JSM 5410, operando em 15 kV (MAIA \& SANTOS, 1997).

\section{RESULTADOS E DISCUSSÃO}

Eletromicrografias obtidas $1 \mathrm{~h}$ após a infecção evidenciaram grande quantidade de conídios aderidos ao tegumento das fêmeas de forma difusa, sem preferência por sítios específicos (Figura 1 A). Resultado semelhante foi obtido por VEY et FARGUES (1977) estudando o processo de infecção do coleóptero Leptinotarsa decemlineata pelo fungo B. bassiana . $\mathrm{Na}$ análise histopatológica, a adesão dos conídios ficou evidenciada pela formação de corpos escuros sobre a cutícula de fêmeas infectadas (Figura 2A) em comparação com a superfície lisa e uniforme da cutícula de fêmeas não infectadas (Figura 2 B). A germinação dos conídios foi evidenciada através de eletromicrografias realizadas $18 \mathrm{~h}$ após a infecção, com vários conídios apresentando a formação de tubos germinativos e estruturas similares a apressórios (Figura $1 \mathrm{~B}$ ). A formação do apressório tem sido relatada (BITTENCOURT, 1999; VESTERGAARD et al., 1999) como um dos eventos principais no processo de penetração de fungos entomopatogênicos no tegumento de hospedeiros e à sua formação associase intensa atividade metabólica necessária para a síntese de exoenzimas que atuam na degradação da cutícula (JOFHI et al., 1997).

A penetração do fungo ocorreu entre $18 \mathrm{e}$ 48h após a infecção e foi observada em diferentes regiões do corpo da fêmea (Figura 1 C). Não se observou a penetração por cavidades ou aberturas naturais do carrapato (aparelho bucal, espiráculos respiratórios, orifício genital e anal), como descrito em insetos infectados por diversas espécies de fungos (ZACARUK, 1970; ALVES, 1986). Contudo, ESTRADA-PENA et al. (1992) relataram a penetração do fungo Aspergillus ochraceus em fêmeas ingurgitadas do carrapato $R$. sanguineus, via ânus.

A característica de penetração via tegumento torna os fungos particularmente promissores no controle de artrópodes sugadores, visto que o aparelho bucal do artrópode fica inserido no corpo de seu hospedeiro, tornando inviável a infecção via oral. A rápida germinação e penetração no corpo do hospedeiro são características importantes para a virulência das linhagens.

A colonização do corpo do carrapato provavelmente ocorreu entre 48 e $72 \mathrm{~h}$ após a infecção tornando-se evidente pela presença de áreas de penetração e escurecimento dos pontos envolvidos, indicando presumida ação enzimática, e a ocorrência de hifas em distribuição centrípeta nos tecidos internos do ácaro (Figura 2C e D). Resultados semelhantes foram obtidos por MOHAMED et al. (1978), quando pesquisaram a ação de Nomuraea rileyi em larvas de Heliothis zea. Todas as fêmeas infectadas morreram entre o 4o e 5 dias após a infecção, sem realizar ovipostura. As amostras processadas e coradas com HE revelaram lesões na cutícula do ácaro e o rompimento da parede intestinal, caracterizado pelo extravasamento do conteúdo para a hemocele do ácaro (Figura 2E), enquanto em todos os períodos pósinfecção analisados, nenhuma alteração digna de nota foi observada nos grupos controle (Figura 2F). A 

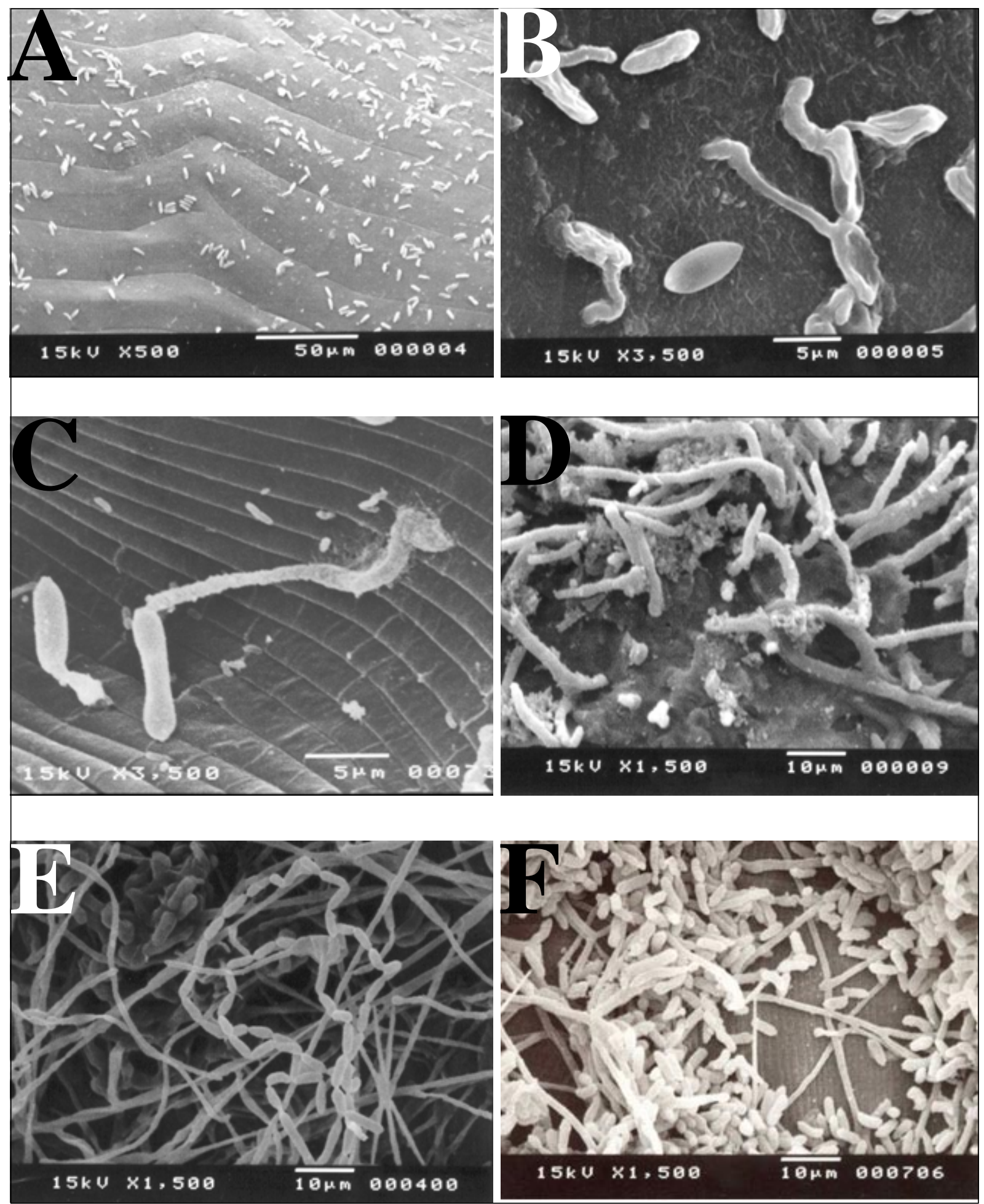

Figura 1 - Eletronmicrografias de varredura de fêmeas ingurgitadas do carrapato Rhipicephalus sanguineus em vários tempos após a infecção experimental com suspensão conidial de Metarhizium anisopliae . A - conídios aderidos à cutícula uma hora após infecção; B - germinação e aparente formação do apressório (apontados por setas) 18 horas após a infecção; C - formação e aparente penetração das hifas na cutícula (apontado por seta) 48 horas após a infecção; D - aparente extrusão (apontados por setas) do fungo; $\mathbf{E}$ e $\mathbf{F}$ - esporulação do fungo na superfície do cadáver do hospedeiro.

Ciência Rural, v.34, n.5, set-out, 2004. 


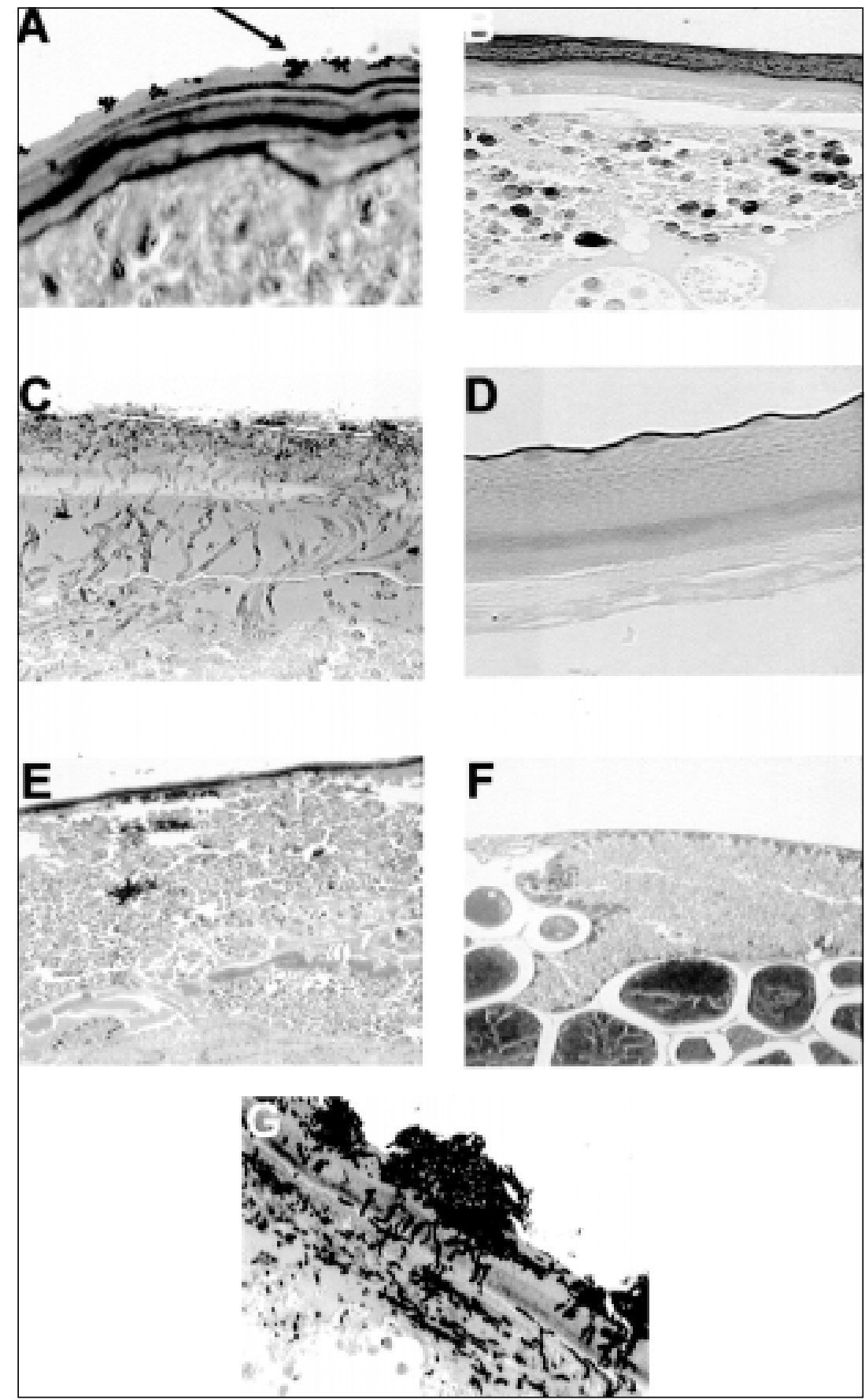

Figura 2 - Fotomicrografias de fêmeas ingurgitadas do carrapato Rhipicephalus sanguineus em vários tempos após a infecção experimental com suspensão conidial de Metarhizium anisopliae. A - início da germinação do conídio sobre a epicutícula (mostrado por seta) 18 horas após a infecção (GMS, 20x); B - controle de A, carrapato não infectado. GMS, objetiva 20x; C - colonização dos tecidos internos do carrapato pelo fungo 48 horas após a infecção (GMS, objetiva 20x); D controle de C (GMS, 20x); E - quatro dias após a infecção, hemocele de carrapato preenchida por conteúdo proveniente de intestino rompido por ação do fungo (HE, objetiva 40x); F - controle de E (HE, objetiva 40x); G - extrusão e esporulação do fungo na superfície do ácaro (GMS, objetiva 40x). suscetibilidade de $\boldsymbol{R}$. sanguineus ao fungo $M$. anisopliae foi investigada por SAMISH (2001) que verificou a morte do ácaro aos 7 dias após a infecção.

Logo após a morte das fêmeas, notou-se os primeiros pontos de crescimento externo (extrusão) do micélio fúngico sobre o cadáver do ácaro, crescimento este que foi progressivamente se generalizando sobre o corpo da fêmea (Figura 1 D). SAJAP \& KAUR (1990) relataram a emergência fúngica e conidiogênese no $4^{\circ}$ dia pósinfecção de Coptotermes curvignathus por $M$. anisopliae.

$\mathrm{No}$

presente estudo, a conidiogênese iniciou-se entre o 6으 $7^{\circ}$ dias após a infecção, e aumentou progressivamente atingindo máxima intensidade no $9^{\circ}$ dia após a infecção (Figuras $1 \mathrm{E}$ e $\mathrm{F}$, e $2 \mathrm{G})$. Crescimento micelial intenso e, conseqüentemente, grande produção de conídios foi verificada praticamente sobre todo o cadáver da fêmea.

\section{CONCLUSÃO}

M. anisopliae é, em testes "in vitro", patogênico de fêmeas ingurgitadas de $\boldsymbol{R}$. sanguineus. A germinação de conídios sobre a epicutícula, bem como a penetração através desta, ocorrem rapidamente. $\mathrm{O}$ fungo coloniza massivamente os tecidos internos do hospedeiro provocando sua morte em poucos dias. Intenso crescimento micelial e alta produção de conídios sobre o cadáver das fêmeas completam o ciclo de desenvolvimento do fungo no ácaro. 


\section{REFERÊNCIASBIBLIOGRÁFICAS}

ALVES, S.B. Controle microbiano de insetos. São Paulo: Manole, 1986. 386p

ARAGÃO, H.B. Ixodidas brasileiros e de alguns países limitrophes. Memórias do Instituto Oswaldo Cruz, v.31, n.4, p.759-841, 1936.

ARAGÃO, H.B.; FONSECA, F. Notas de Ixodologia. VII. Lista e chave para os representantes da fauna ixodológica brasileira. Memórias do Instituto Oswaldo Cruz, v.59, n.2, p.115-130, 1961 .

BARBOSA, J.V. et al. Efeitos de dois isolados do fungo Beauveria bassiana (Bals.) Vuill., sobre a muda larval e sobrevivência de ninfas de Rhipicephalus sanguineus (Latreille, 1806) (Acari: Ixodiade). Revista Brasileira de Parasitologia Veterinária, v.6, n.1, p.53-56, 1997.

BECHARA, G.H. et al. Development of immunity to Rhipicephalus appendiculatus in hamsters (Mesocricetus auratus). Immunobiology, v.4, p.176, 1989.

BITTENCOURT, V.R.E.P. et al. Efficacy of two isolates of Beauveria bassiana in engorged females of Boophilus microplus in the laboratory. Revista da Universidade Rural, Série Ciência da Vida, v.19, n.1-2, p.65-71, 1997.

BITTENCOURT, V.R.E.P.; MASCA-RENHAS, A.G.; FACCINI, J.L.H. The penetration of the fungus Metarhizium anisopliae on Boophilus microplus in experimental conditions. Ciência Rural, Santa Maria, v.29, n.2, p.351354, 1999.

ESTRADA-PENÃ, A.; JONGEJAN, F. Ticks feeding on humans: a review of records on human-biting Ixodoidea with special reference to pathogen transmission. Experimental and Applied Acarology, v.23, p.685-715, 1999

ESTRADA-PENÃ, A.; GONZALES, J.; CASASOLAS, A. The activity of Aspergillus ochraceus (Fungi) on replete females of Rhipicephalus sanguineus (Acari: Ixodidae) in natural and experimental conditions. Folia Parasitologica. v.37, n.4, p.331-336, 1992 .

JOFHI, L.; ST. LEGER, R.J.; ROBERTS, D.W. Isolation of a cDNA enconding anovel subtilisin like protease (Pr1 B) from the entomopatogenic fungus, Metarhizium anisopliae using diferential display - RT-PCR. Revista Geni, v.197, p.1-8, 1997.

LABRUNA, M.B.; PEREIRA, M.C. Carrapato em cães. Clinica Veterinária, v.6, p.24-32, 2001.

MAIA, A.S.; SANTOS, J.M. dos. A SEM technique for preparing biological control agents of nematodes in action. Acta Microscopic, v.6, s.B, p.550-551, 1997.
MOHAMED, A.K.A.; SIKOROWSKI, P.P.; BELL, J.V. Histopathology of Nomuraea rileyi in larvae of Heliothis zea and in vitro enzimatic activity. Journal of Invertebrate Pathology v.31, p.345-352, 1978

MILLER, R.J. et al. Characterization of acaricide resistence in Rhipicephalus sanguineus (Latreille) (Acari: Ixodidae) collected from the Corozal Army Veterinary Quarentine Center, Panama. Journal of Medical Entomology, v.38, n.2, p.298-302, 2001

MONTEIRO, S.G. et al. Ação dos fungos Beauveria bassiana e Metarhizium anisopliae em larvas do carrapato Rhipicephalus sanguineus. Ciência Rural, Santa Maria, v.28, n.3, p.461-466, 1998 .

PEGRAM, R.G. et al. Clarification of de Rhipicephalus sanguineus group (Acari, Ixodoidea, Ixodidae). II. $\boldsymbol{R}$. sanguineus (Latreille, 1806) and related species. Systematic Parasitology, v.10, p.27-44, 1987.

RIBEIRO, V.L.S. et al. Espécies de prevalência das infestações por carrapatos em cães de rua da cidade de Porto Alegre, RS, Brasil. Ciência Rural, Santa Maria, v.27, n.2, p.285-289, 1997.

SAJAP, A.S.; KAUR, K. Histopathology of Metarhiziun anisopliae, an entomopathogenic fungus, infection on the termite, Coptotermes curvignathus. Pertanika, v.13, n.3, p.331-334, 1990

SAMISH, M. et al. Pathogenicity of entomopathogenic fungi to different developmental stages of Rhipicephalus sanguineus (Acari: Ixodidae). Journal Parasitology, v.38, n.6, p.13551359, 2001 .

SZABÓ, M.P.J. et al. Ticks (Acari: Ixodidae) associated with domestic dogs in Franca region, São Paulo, Brazil. Experimental and Applied Acarology, v.25, p.909-916, 2001

VEY, A.; FARGUES, J. Histological and ultrastructural studies of Beauveria bassiana infection in Leptinotarsa decemlineata larvae during ecdysis. Journal of Invertebrate Pathology, v.30, p.207-215, 1977.

VESTERGAARD, S. et al. Light and electron microscopy studies of the infection of the western flower trips Frankliniella occidentalis (Thysanoptera: Thripidae) by the entomopathogenic fungus Metarhizium anisopliae. Journal of Invertebrate Pathology, v.73, p.25-33, 1999

WALKER, J.B.; KEIRANS, J.E.; HORAK, I.G. The Genus Rhipicephalus (Acari, Ixodidae). A guide to the brown ticks of the world. Cambridge : Cambridge University, 2000. 643p.

ZACHARUK, R.Y. Fine structure of the fungus Metarhizium anisopliae infecting three species of larval Elateridae (Coleoptera). II Conidial germ tubes and appressoria. Journal of Invertebrate Pathology, v.15, p.81-91, 1970. 